\title{
Impact of changing environments on the gut microbiome of a migratory songbird
}

\author{
Heather Skeen ${ }^{1}$, Nathan Cooper ${ }^{2}$, Shannon Hackett ${ }^{3}$, John Bates ${ }^{3}$, and Peter Marra ${ }^{4}$ \\ ${ }^{1}$ University of Chicago \\ ${ }^{2}$ Smithsonian Conservation Biology Institute \\ ${ }^{3}$ Field Museum of Natural History \\ ${ }^{4}$ Georgetown University
}

October 8, 2020

\begin{abstract}
Migratory animals experiencing substantial change in diet and habitat across the annual cycle may have corresponding shifts in host-associated microbial diversity. Using automated telemetry and radio tags to recapture birds, we examined gut microbiome structure in the same population and often same individuals of Kirtland's Warblers (Setophaga kirtlandii) on their wintering grounds in The Bahamas and breeding territories in Michigan, USA. The community composition of gut microbiota varied significantly between locations with microbial diversity decreasing from The Bahamas to Michigan. We identified a speciesspecific core microbial profile that spans multiple time periods and environments. Our research highlights, at the individual and population level, that the avian gut microbiome is dynamic over time and is significantly impacted by changing environments associated with migration. These results support the need for full annual cycle monitoring of migratory bird microbiota to improve understanding of seasonal host movement ecologies and response to recurrent physiological stressors.
\end{abstract}

\section{Hosted file}

Skeen_etal_KWMB_main.pdf available at https://authorea.com/users/365153/articles/485373impact-of-changing-environments-on-the-gut-microbiome-of-a-migratory-songbird

\section{Hosted file}

Skeen_etal_KWMB_figures.pdf available at https://authorea.com/users/365153/articles/485373impact-of-changing-environments-on-the-gut-microbiome-of-a-migratory-songbird

\section{Hosted file}

Skeen_etal_KWMB_SuppFigures.pdf available at https://authorea.com/users/365153/articles/ 485373-impact-of-changing-environments-on-the-gut-microbiome-of-a-migratory-songbird 